\title{
REFLEXÕES LEIGAS PARA A FORMULAÇÃO DE UMA AGENDA DE PESQUISA EM POLÍTICAS PÚBLICAS
}

\author{
Elisa P. Reis
}

No contexto do tema geral desse evento Ciência Política e Justiça Social - parece-me oportuno lembrar algumas questões que permeiam toda a prática da ciência social e, em particular, da ciência política. Quero, contudo, pensar isso no caso específico da subárea de políticas públicas. O tema é importante demais para ser reservado exclusivamente aos especialistas. Considero as questões a serem discutidas tão centrais que sinto-me a vontade para refletir sobre alguns pontos, ainda que, pessoalmente, eu não seja uma pesquisadora dessa área e sim uma consumidora de seus resultados de pesquisa.

Como ponto de partida, quero chamar atenção para o fato de que "políticas públicas" é uma das especializações que responde mais diretamente ao imperativo da relevância na prática das ciências sociais. Seja analisando a formulação, a implementação ou os resultados de policies, os especialistas podem ver de maneira bastante cla- ra e imediata como suas análises interpelam situações concretas, examinam tecnicamente problemas empíricos específicos e podem servir para legitimar ou deslegitimar as escolhas políticas efetivas. É precisamente esse aspecto da relevância prática que mais me atrai nessa área. Ou seja, o fato de que, em princípio, ela não se furta ao imperativo da utilidade social e que, mesmo quando adota uma postura crítica, ela o faz apostando na possibilidade de cursos de ação alternativos. Em outras palavras, trata-se de uma área propositiva, pelo menos em tese.

É importante salientar, porém, que contrariamente a uma crença errônea, mas persistente, a preocupação com a relevância não significa que as reflexões teóricas são rebaixadas a segundo plano. É claro que o especialista em políticas públicas pode se refugiar no território técnico. Entretanto, para fazer de sua prática, mais do que uma rotina técnica, uma prática de ciência social, ele 
não pode se furtar ao exercício de uma análise teórica, seja da perspectiva da ciência política, seja da sociologia política. Em outras palavras, o cientista social que se dedica à política pública precisa ter clareza tanto em relação à perspectiva teórica em que está inserido seu trabalho, quanto em relação às discussões que confrontam essa perspectiva com outras, alternativas a ela.

Além disso, analisar a viabilidade política de uma determinada policy é uma questão tão técnica quanto as de natureza instrumental específicas a cada issue. Mas, essa é também uma questão tão moral quanto aquelas que inspiraram Marx e Weber. Nesse sentido, qualquer que seja o ângulo da política pública contemplado por um pesquisador, as questões morais, teóricas e técnicas encontram-se bastante interligadas.

É evidente que não se exige de ninguém que, a cada texto ou a cada discussão, se detenha na consideração das pressuposições analíticas que sustentam sua análise. Tampouco se espera uma confissão de fé em determinado paradigma teórico ou uma explicitação recorrente de preferências normativas. Mas, deve-se esperar sim que o cientista político tenha claro em que campo teórico se inscreve seu trabalho e quais os principais competidores desse marco. Isso é condição básica para que o diálogo intelectual seja frutífero.

Nesse sentido, o primeiro ponto que eu lembraria para uma agenda de pesquisas em políticas públicas é que os projetos tenham uma sustentação teórica. Isso parece demasiado óbvio para requerer atenção. Contudo, na prática vemos que com muita freqüência descuramos desse princípio. Talvez o problema seja mais agudo na prática do ensino do que na da pesquisa em políticas públicas, mas em ambos os casos vale a pena enfatizar que nós nos beneficiamos e muito ao adotar uma postura atenta aos parâmetros teóricos que modelam nossas análises, por mais empíricas que sejam.

O problema inverso deve nos preocupar igualmente. Pesquisas e cursos que são rotulados como análises de políticas públicas, na realidade, apenas se referem a policies, sem tratá-las de forma específica e sistemática. Em muitos casos, a indignação moral é tomada como justificativa teórica.
Para alguém, como eu, que tem uma visão de fora da área, quais seriam os temas candentes? Que temáticas privilegiar nessa agenda? Sem dúvida, a gama de temas e problemas a serem investigados é imensa e são vários os critérios ordenadores que poderiam ser invocados para se elaborar as prioridades de pesquisa. O que é que esperaríamos ver enfatizado pelos especialistas? De fato, parece-me que a comunidade acadêmica tem respondido bem aos desafios do momento e a prova disso pode ser vista no próprio programa desse evento. Os trabalhos listados cobrem uma vasta gama de aspectos da política pública, muitos deles lidando com realidades novas e desafiadoras em nosso contexto. Eu iria ainda mais longe para sugerir que os títulos dos painéis programados para esse Grupo de Trabalho nos sugerem uma excelente agenda de pesquisa para a área.

O que gostaria de propor para reflexão não é uma listagem de temas relevantes para uma agenda de pesquisa, mas uma moldura geral para a discussão. Como "observadora externa" não estaria apta a identificar os pontos fortes e fracos do estado das artes dessa subárea. Isso é tarefa para a comunidade interna. Considero, porém, legítimo um esforço de minha parte para sugerir um arcabouço teórico geral onde possa ser situada uma agenda de pesquisa em análise de políticas públicas. Entendo a expressão "agenda de pesquisa" no sentido da filosofia da ciência, ou seja, como um programa de trabalho que define uma comunidade científica. Nesse contexto, minhas observações devem ser vistas como considerações teóricas sobre a inserção de temáticas de pesquisa no quadro geral das questões políticas, econômicas e sociais que desafiam o mundo hoje.

Acho proveitoso partir da constatação de que as relações entre recursos de autoridade e recursos de mercado, por um lado, e entre critérios de autoridade e critérios de solidariedade, por outro, passaram por modificações profundas no período histórico recente.

No caso do primeiro pólo, o surpreendente revival do liberalismo a que assistimos levou a uma súbita erosão da legitimidade do Estado como agente econômico no Segundo e no Terceiro mundo. O que mais me impressiona aqui é a 
rapidez com que crenças firmemente estabelecidas no âmbito da academia e no âmbito dos governos foram suplantadas quase da noite para o dia. Subitamente, por exemplo, os livros sobre desenvolvimento e planejamento caducaram, deixando anômicos os especialistas no assunto.

No caso dos países ex-socialistas, as tendências mais recentes sugerem que tanto o governo quanto o mercado começam a dar sinais de se reequilibrarem, mas busca-se avidamente um arcabouço teórico e ideológico capaz de sistematizar novos arranjos. Já no caso da América Latina, se a situação econômica e social é menos animadora, não deixa de ser claro que o eclipse do Estado desenvolvimentista deixou um enorme vazio ideológico que introduz aqui e ali novas incertezas políticas. Nesse novo contexto, a análise e a discussão de políticas públicas pode ser vítima de um tecnicismo exagerado, e isso é o que muitas vezes se critica nas análises dos economistas.

O problema inverso é também bastante disseminado, ou seja, a negação dos constrangimentos técnicos em favor de uma adesão a-crítica a ideais doutrinários no mais das vezes arcaicos e anacrônicos. Pois bem, a nós cientistas políticos, sociólogos e antropólogos caberia o empenho de analisar policies como práticas políticas, práticas essas onde a interação entre interesses, valores e normas merece tanta consideração quanto os critérios técnicos e as restrições orçamentárias.

Lembraria também que a erosão do ideário planificador (socialista ou capitalista) deu ensejo a uma situação nova onde a formulação de policies constitui causa e efeito das mudanças político-institucionais em curso. Poucas conjunturas são tão propícias a evidenciar a dinâmica interativa entre instituições e motivações individuais. Um programa de pesquisa amplo que se dedicasse a explorar essa questão, comparando tanto as diversas formas institucionais quanto as motivações variáveis de atores estratégicos que atuam nelas, ou com elas, seria extremamente relevante não só em termos teóricos, mas também práticos.

Quero enfatizar aqui tanto o foco simultâneo na instituição e no ator, como o recurso à comparação. O primeiro aspecto permite-nos captar o jogo entre constrangimento e liberdade, entre li- mitações paramétricas e voluntarismo. Mas é o segundo, a comparação sistemática, que nos faculta as condições para checarmos o alcance de nossas explicações e interpretações. Nunca é demais insistir que a comparação é nossa melhor proxi a uma situação experimental. Esses seriam, portanto, na minha opinião, os elementos preliminares de uma agenda de pesquisa em políticas públicas. É preciso assumir o compromisso de articular as perspectivas individualista e institucional. Isso me parece o desafio crucial, desafio que é tanto teórico como prático.

Voltemos à linha central de meu argumento, a idéia segundo a qual as relações entre autoridade, mercado e solidariedade passam por mudanças profundas no momento atual. No que diz respeito à interação entre autoridade e solidariedade, as transformações não são menos relevantes. Assim, por exemplo, as transformações recentes nas relações entre o Estado e a nação são igualmente dignas de nota: identidades coletivas são redefinidas por toda parte, cruzando fronteiras e desafiando autoridades nacionais. Mas, na medida em que a política pública continua sendo definida no contexto dos Estados nacionais, quero me deter apenas em outra dimensão desse relacionamento entre autoridade e solidariedade, o que concerne às organizações voluntárias - ONGs, instituições filantrópicas etc. Também aqui observamos um movimento notável em escala mundial que cria um novo tipo de ator relevante para a prática da política pública, o chamado Terceiro Setor, reino da solidariedade.

Em síntese, é necessário reexaminarmos as relações do Estado com o mercado, por um lado, e com a sociedade civil, por outro. No primeiro caso, parece-me que à área de políticas públicas compete, por exemplo, analisar como é que o Estado age e/ou poderia agir para assegurar a provisão de bens públicos que não são mais produzidos e/ou distribuídos pelo setor público. Nesse sentido, a análise das agências de regulação é um dos objetos de estudo cruciais. Como são concebidas essas novas instituições? Quais suas atribuições? Como vêm desempenhando seu papel de articuladoras entre a autoridade pública e o mercado provisor de bens públicos? De que maneira 
suas atribuições e prerrogativas constituem obstáculos ou recursos para a eficácia de políticas públicas específicas? Enfim, há toda uma série de questões da maior relevância para a análise de políticas públicas que, para serem respondidas, precisam que o formato institucional e a prática dessas agências sejam esclarecidos.

Com relação ao binômio autoridade/solidariedade, seria de extrema relevância pesquisar os novos padrões de funcionamento da política social, que conta mais e mais com o voluntariado. Noções como "democracia participativa", "capital social", "inclusão social", "governança" e tantas outras que incorporamos ao nosso léxico nas décadas recentes têm, certamente, inspirado estudos de grande interesse e importância. Mas, é oportuno lembrar que a componente virtuosa associada a cada um desses conceitos não nos dispensa do exame crítico, sem o qual a prática da análise política perde sua dimensão científico-reflexiva para tornar-se prática política.

Cabe examinar, por exemplo, as conseqüências do recurso cada vez mais utilizado à atuação da sociedade civil em contextos onde a extrema desigualdade torna difícil postular uma sociedade civil no singular. Se os custos de organização e de participação são tão desiguais dentro de um país, faz sentido falar de uma sociedade coincidente com o Estado nacional? Não é só a globalização que coloca desafios ao Estado nacional. Interage estreitamente com ela um paralelismo entre setores sociais que experimentam condições e oportunidades de vida tão desiguais. Nesse contexto, o próprio engajamento da sociedade civil pode implicar novas formas de oligarquização de recursos.

Ou seja, onde os custos e as oportunidades de participação dos cidadãos são tão desiguais, os que já estão incluídos podem vir a aumentar suas vantagens relativas em relação aos excluídos. A lógica do capital social pode comportar tanta formação de monopólios quanto a do mercado. O que estou sugerindo é que a agenda de pesquisa em políticas públicas deveria incluir entre suas preocupações o exame crítico da interação entre o ator público e o voluntariado na execução de policies. Não se trata de demonizar esse ator, mas simples- mente de adotar uma postura crítica e analítica ante um ator ainda pouco estudado pela área.

Também gostaria de ressaltar a importância de se inserir no quadro geral de orientações a modelar uma agenda de pesquisa em políticas públicas a questão das tensões e possíveis contradições entre os princípios orientadores da ação. Universalismo e ação focalizada, afirmação da igualdade e afirmação das diferenças são termos que povoam os discursos de teóricos e práticos sobre a afirmação da cidadania. No entanto, a discussão a respeito disso poucas vezes se volta para a análise sistemática de resultados a curto ou a longo prazo de políticas sociais que privilegiem um ou outro dos termos dessas disjuntivas. Aqui, poderse-ia abrir um amplo leque de estudos extremamente importantes, tanto no interior da área de políticas públicas como no âmbito da ciência política como um todo. Isto é, essa discussão diz respeito ao próprio escopo da cidadania hoje, tema que se situa no cerne da teoria social e política.

Enfim, essas são minhas sugestões gerais, preliminares à elaboração de uma agenda de pesquisa em políticas públicas. Sugestões, conforme já mencionei, de uma simples usuária de resultados de pesquisa produzidos pela área. 


\section{REFLEXÕES LEIGAS PARA A FORMULAÇÃO DE UMA AGENDA DE PESQUISA EM POLÍTICAS PÚBLICAS}

Elisa P. Reis

\section{Palavras-chave}

Teoria e pesquisa; Estado-nação; Autoridade e mercado; Autoridade e solidariedade.

O que deve integrar a agenda de pesquisa da área de políticas públicas? Este texto reproduz os comentários feitos pela autora a esse propósito. A autora destaca, particularmente, a importância da dimensão teórica subjacente às questões de pesquisa. Sugere, ainda, que os processos de mudança que permeiam toda a sociedade contemporânea impulsionam também mudanças no arcabouço teórico e conceptual que modela a maneira como vemos as relações do Estado nacional com o mercado e a sociedade.

\section{OUTSIDER'S CONSIDERA- TIONS FOR THE FORMULA- TION OF AN AGENDA ON PU- BLIC POLICIES RESEARCH}

Elisa P. Reis

\section{Key words}

Theory and research; Nation-State Authority and market; Authority and solidarity.

To answer the question "what should be included in the research agenda of the specialist in public policies?" the author chooses to comment on theoretical issues that she thinks should not be neglected. She suggests that the processes of change that pervade contemporary societies make it necessary to introduce changes also in the theoretical and conceptual frames that inform the way we see the interaction of the nation-state with both market and society.

\section{RÉFLEXIONS LIBRES POUR LA FORMULATION D'UN AGENDA DE RECHERCHE EN SCIENCES POLITIQUES}

Elisa P. Reis

\section{Mots-clés}

Théorie et recherche; État-nation; Autorité et marché; Autorité et solidarité.

Que doit intégrer l'agenda de recherche dans le domaine des politiques publiques? Ce texte transcrit les commentaires faits par l'auteur à ce propos. L'auteur souligne, particulièrement, l'importance de la dimension théorique sous-jacente aux questions de recherche. Elle suggère aussi que les processus de changement qui passent par toute la société contemporaine donnent également une impulsion aux changements dans le squelette théorique et conceptuel qui donne forme à la façon par laquelle nous concevons les relations entre l'État national avec le marché et la société. 